\title{
Neonatal screening and a new cause of congenital central hypothyroidism
}

Toshihiro Tajima, MD, PhD, Akie Nakamura, MD, Shuntaro Morikawa, MD, Katsura Ishizu, MD

Department of Pediatrics, Hokkaido University School of Medicine, Sapporo, Japan
Received: 3 August, 2014

Accepted: 14 August, 2014

Address for correspondence:

Toshihiro Tajima, MD, PhD

Department of Pediatrics, Hokkaido University School of Medicine, N15, W7, Kita-Ku, Sapporo 060-8638, Japan

Tel: +81-11-716-1161

Fax: +81-11-706-7898

E-mail: tajeari@med.hokudai.ac.jp
Congenital central hypothyroidism $(\mathrm{C}-\mathrm{CH})$ is a rare disease in which thyroid hormone deficiency is caused by insufficient thyrotropin (TSH) stimulation of a normally-located thyroid gland. Most patients with $\mathrm{C}-\mathrm{CH}$ have low free thyroxine levels and inappropriately low or normal TSH levels, although a few have slightly elevated TSH levels. Autosomal recessive TSH deficiency and thyrotropin-releasing hormone receptor-inactivating mutations are known to be genetic causes of $\mathrm{C}-\mathrm{CH}$ presenting in the absence of other syndromes. Recently, deficiency of the immunoglobulin superfamily member 1 (IGSF1) has also been demonstrated to cause C-CH. IGSF1 is a plasma membrane glycoprotein highly expressed in the pituitary. Its physiological role in humans remains unknown. IGSF1 deficiency causes TSH deficiency, leading to hypothyroidism. In addition, approximately $60 \%$ of patients also suffer a prolactin deficiency. Moreover, macroorchidism and delayed puberty are characteristic features. Thus, although the precise pathophysiology of IGSF1 deficiency is not established, IGSF1 is considered to be a new factor controlling growth and puberty in children.

Keywords: Congenital hypothyroidism (CH), Neonatal screening, Thyrotropin (TSH), IGSF1

\section{Introduction}

Congenital central hypothyroidism $(\mathrm{C}-\mathrm{CH})$ is an unusual condition characterized by low levels of both thyroid hormones and of thyroid-stimulating hormone (TSH). Patients with this disorder cannot be identified by neonatal screening programs based on TSH measurements ${ }^{1,2)}$. However, neonatal screening for $\mathrm{CH}$ on the basis of thyroxine (T4) or free T4 and TSH concentrations can be performed to diagnose this type of $\mathrm{CH}^{1-6)}$.

$\mathrm{C}-\mathrm{CH}$ is caused by mutations of transcription factors involved in pituitary development and differentiation, including POU1F, PROP1, HESX1, LHX3, and LHX ${ }^{7-9)}$. Because more than one pituitary cell type is deficient in these genetic diseases, patients with mutations of transcription factors often present with as a multiple pituitary hormone deficiency ${ }^{7-9)}$. On the other hand, $\mathrm{C}-\mathrm{CH}$ presenting in the absence of other syndromes remains a rare disease and is due mainly to a genetic deficit of the $\beta$-subunit of TSH (OMIM 188540$)^{10,11)}$ or mutations of the thyrotropin-releasing hormone (TRH) receptor (OMIM 188545) ${ }^{12,13}$. Recently, it has been demonstrated that deficiency of immunoglobulin superfamily member 1 (IGSF1) (OMIM 300888) can also be a cause of $\mathrm{C}-\mathrm{CH}^{14-17}$. This review will focus on clinical findings in patients with mutations of $I G S F 1$, and the molecular basis of their disease.

\section{Immunoglobulin superfamily member 1}

IGSF1 is a plasma membrane immunoglobulin superfamily glycoprotein ${ }^{18,19)}$. This protein has a putative signal peptide and twelve $\mathrm{C} 2$ type immunoglobulin (Ig)-like domain loops, a transmembrane domain, and a short intracellular $\mathrm{C}$ tail ${ }^{19)}$ (Fig. 1). The protein is 
cotranslationally cleaved such that only the C-terminal domain, containing 7 Ig loops, reaches the plasma membrane ${ }^{19)}$. The gene encoding IGSF1 is located on Xq 26.2 ${ }^{18}$. Human IGSF1 and murine Igsf1 mRNAs are highly expressed in Rathke's pouch and in adult pituitary gland and testis ${ }^{14)}$. Moreover, IGSF1 protein is expressed in murine thyrotropes, somatotropes, and lactotropes, but not in gonadotropes or in the testis ${ }^{14)}$.

IGSF1 was initially hypothesized to be a candidate for the inhibin coreceptor in the pituitary gland, and it was therefore designated inhibin binding protein or p $120.5^{20)}$. However, Igs $f 1$ knockout mice showed no alternation of follicle stimulating hormone synthesis or secretion, and normal fertility ${ }^{211}$. Moreover, a recent in vitro study did not demonstrate binding of inhibin and IGSF ${ }^{22}$. Thus, the physiological function of IGSF1 remains unknown.

Members of the IgSF have a wide variety of functions, acting as cell surface antigen receptors, coreceptors and costimulatory molecules of the immune system, molecules involved in antigen presentation to lymphocytes, cell adhesion molecules, certain cytokine receptors, and intracellular muscle proteins ${ }^{23-28}$. Some IgSF members play crucial roles not only in nervous system development but also in the adult during neural repair and synaptic plasticity ${ }^{26-28)}$. Considering the function of other IgSF family members, IGSF1 may also act as a signal transduction molecule and/or cell adhesion molecule in the pituitary.

\section{Neonatal screening for $\mathrm{C}-\mathrm{CH}$ in Japan}

In Sapporo city, the neonatal screening program for congenital hypothyroidism has employed the measurement of free $\mathrm{T} 4$ and TSH in the same filter-paper blood spot since 1986. This system has enabled us to identify $\mathrm{C}$ - $\mathrm{CH}$ in the neonatal period. Between January 2000 and December 2004, 83,232 newborns were screened and six C-CH patients identified as a result of follow-up of low free T4 and nonelevated TSH screening test results (a frequency of one in 13,872$)^{4}$. Clinical characteristics and neonatal screening data of these patients are summarized in Table 1. Four showed multiple pituitary hormone deficiencies with pituitary malformations on magnetic resonance imaging. One patient was diagnosed as having Prader-Willie syndrome. Of these 6 , the C-CH of a single one was caused by IGSF 1 deficiency.
Adachi et al. $\left.{ }^{6}\right)$ have recently reported the prevalence of $\mathrm{C}-\mathrm{CH}$ in Kanagawa prefecture between 1999 and 2008. According to their study, neonatal screening for free thyroxine and TSH identified $24 \mathrm{C}-\mathrm{CH}$ patients, 14 of whom had multiple pituitary hormone deficiencies, eight had isolated $\mathrm{C}-\mathrm{CH}$, and two had undetermined pituitary involvement. Thus, the prevalence of $\mathrm{CH}-\mathrm{C}$ was estimated at 1 in 30, 833 live births. During this period, 213 patients with $\mathrm{CH}$ of thyroid origin were diagnosed. Thus, $\mathrm{C}-\mathrm{CH}$ constituted $10 \%$ of permanent $\mathrm{CH}$ detected by neonatal screening.

Lanting et al. ${ }^{3)}$ have reported the results of a neonatal screening program based on initial T4 and subsequent TSH determination with a T4 binding globulin in the Netherlands. In their study, among 385,000 infants screened during the period 1995-2000, the incidence of C-CH was 1:16,404 with $75 \%$ of $\mathrm{C}-\mathrm{CH}$ diagnosed as having multiple pituitary hormone deficiency. This suggests that the incidence of isolated C-CH is likely to be around 1:65,000. Moreover, Joustra et al. ${ }^{17)}$ reported an IGSF1 defect in 8 of 11 patients with isolated C-CH. Therefore, it is postulated that the incidence of $\mathrm{C}-\mathrm{CH}$ caused by IGSF1 deficiency is approximately 1:100,000.

As mentioned above, in our small study over the short period 2004 to 2008 , only one patient had a IGSF1 deficiency ${ }^{4)}$. Thus, the incidence of IGSF1 deficiency was 1 in 80,000, but the exact prevalence of C-CH caused by IGSF1 deficiency in Japan cannot be said to have been determined. Further study is required.

\section{Phenotypes associated with IGSF1 deficiency}

In a previous report, six familial cases of $\mathrm{C}-\mathrm{CH}$ in the Netherlands and one in Italy were identified by neonatal screening ${ }^{14)}$. We have identified three IGSFI-deficient patients by neonatal screening ${ }^{15,16}$. ${ }^{123}$ I scintigraphy showed a normalsized thyroid in our patients. The Dutch study also showed normal-sized thyroids by ultrasound, except in one case ${ }^{14)}$.

In our study, one patient who was not identified by TSH screening in the neonatal period suffered growth retardation, and here, medical examination led to the diagnosis of growth hormone (GH) deficiency and central hypothyroidism at 4 years of age. We also diagnosed GH deficiency in one other patient. Joustra et al. ${ }^{17)}$ reported 3 patients with GH deficiency together with $\mathrm{CH}$, but when $\mathrm{GH}$ secretion was reevaluated in two

Table 1. Patients with C-CH detected by neonatal screening in Sapporo city during 2004 to 2008

\begin{tabular}{|c|c|c|c|c|}
\hline Patient & Diagnosis & Brain anomaly & FT4 at screening (ng/dL) & TSH at screening $(\mathrm{U} / \mathrm{L})$ \\
\hline 1 & Prader-Willi & & 0.78 & $<0.5$ \\
\hline 2 & MPHD (TSH, GH, LH, FSH, PRL, ACTH) & Hypo AP, Ectopic PP, Right optic nerve atrophy & 0.75 & 1.3 \\
\hline $3^{\mathrm{a})}$ & TSH deficiency & Normal & 0.68 & 1.2 \\
\hline 4 & MPHD (TSH, GH, ACTH) & Hypo AP, Ectopic PP & 0.96 & 3.2 \\
\hline 5 & MPHD (TSH, GH) & Ectopic PP, Invisible stalk & 0.62 & 3.1 \\
\hline 6 & MPHD (TSH, GH) & Invisible stalk, Bilateral optic nerve atrophy & 0.75 & 3.3 \\
\hline
\end{tabular}


patients at adolescence, it was shown to be normal. It is possible that untreated hypothyroidism may impair GH secretion. Alternatively, because IGSF1 is expressed in somatotropes ${ }^{14)}$, an IGSF1 defect in these cells may affect GH secretion.

Four of our 5 patients had low levels of prolactin. The Dutch study found that $16 / 24$ had hypoprolactinemia ${ }^{17)}$. Thus, prolactin deficiency is one of the clinical features of IGSF1 deficiency.

Because TSH-based neonatal screening cannot identify patients with IGSF1 deficiency, treatment with thyroxine is delayed in those patients undergoing TSH screening. Therefore, there is a concern that psychomotor development may be delayed by late onset of treatment. However, several family members of affected patients showed no symptoms and their hypothyroxinemia was mild ${ }^{14,17)}$. Their intelligence quotient seemed to be within the normal range. By contrast, in our study, one patient whose treatment was started at 4 years of age showed slightly delayed development ${ }^{16)}$. Thus, it is still possible that severe cases of IGSF1 deficiency might be accompanied by developmental delay. Three of our patients did have delayed puberty and their serum luteinizing hormone and FSH levels remained at prepubertal levels even at 12 years of age. In the

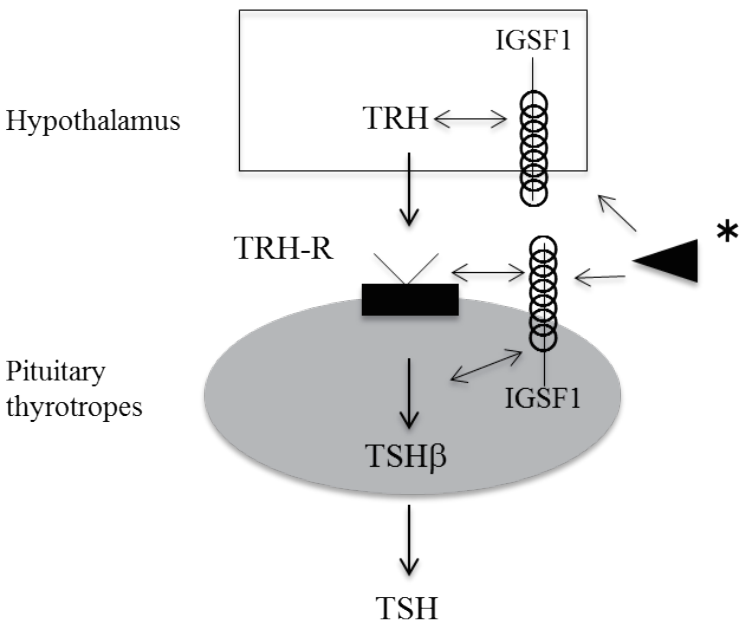

Fig. 1. Speculated function of IGSF1 in pituitary TSH synthesis and secretion. IGSF1 is likely to affect TSH synthesis, secretion and pituitary TRH receptor function. In addition, as IGSF1 is also expressed in hypothalamus, IGSF1 may affect TRH secretion. IGSF1, immunoglobulin superfamily member 1; TSH, thyroid-stimulating hormone; TRH, thyrotropin-releasing hormone. *, Arrowhead indicates that undetermined IGSF1 ligand may interact with IGSF1 on cell surface, and thus may modulate TRH-TRH receptor signaling. report of Sun et al. ${ }^{14)}, 10$ of 11 evaluated patients showed delayed testosterone production and pubertal growth. Delayed secondary sex characteristics may therefore be one of the clinical hallmarks in patients with pathogenic IGSF1 mutations. In addition, testicular enlargement after adolescence is a characteristic feature of IGSF1 deficiency. It has been reported that all such patients aged more than 12 years manifested macroorchidism. In our study, two patients showed increased testicular size at 13 years of age $(14 \mathrm{~mL}$ according to the Prader orchidometer) but one other had normal sized testes at 17 years of age. It has been suggested that testicular size increases from young to late adulthood. Thus, in this case testicular size may be increased in the future. Despite macroorchidism, fertility of male patients is likely to be normal ${ }^{14,17)}$.

We performed a TRH test twice in one patient. Compared with the result of the first TRH test, serum TSH was markedly reduced in the second test ${ }^{16)}$. It has been observed that in Igsf1 knockout mice, pituitary TSH synthesis and secretion are reduced, and pituitary TRH receptor mRNA expression is decreased ${ }^{14)}$. It was speculated, therefore, that reduced TRH receptor signaling might be one of the pathogenic mechanisms of C-CH in IGSF1-deficient patients. TRH signaling through the TRH receptor is known to be an important factor for normal proliferation of thyrotropes ${ }^{29,30)}$, so in patients with IGSF1 defects, their proliferation during postnatal development may be impaired. This may indicate that IGSF1 is involved in thyrotrope proliferation and differentiation, in addition to TSH secretion (Fig. 1).

Joustra et al. ${ }^{17)}$ have analyzed metabolic parameters of children and adolescents with IGSF1 deficiency. They found that body mass index (BMI) was increased in 3 of 7 patients, and percentage of fat was high in 5 . In adult cases, most patients showed increased BMI and fat, but this is not likely to be due to hypothyroidism, because patients who were treated from early infancy also showed these findings, as well as untreated individuals. This may suggest that obesity is not caused by hypothyroidism but rather a direct effect of IGSF1 deficiency itself. In our studies, the BMI of three patients was 18.5, 24.0, and $25.2 \mathrm{~kg} / \mathrm{m}^{2}$ at 12 years of age. Two patients showed higher BMI for their age than normal Japanese children ${ }^{31)}$, and thus careful follow-up for metabolic parameters is also necessary in IGSF1 deficiency.

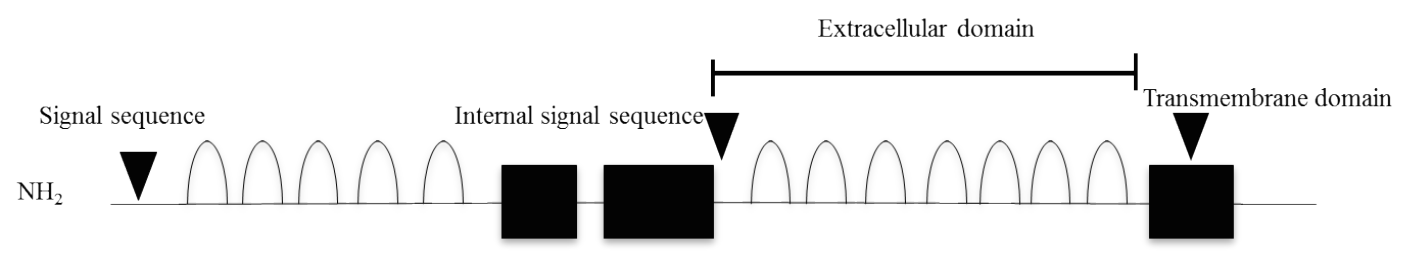

Fig. 2. Schematic representation of immunoglobulin superfamily member 1. 


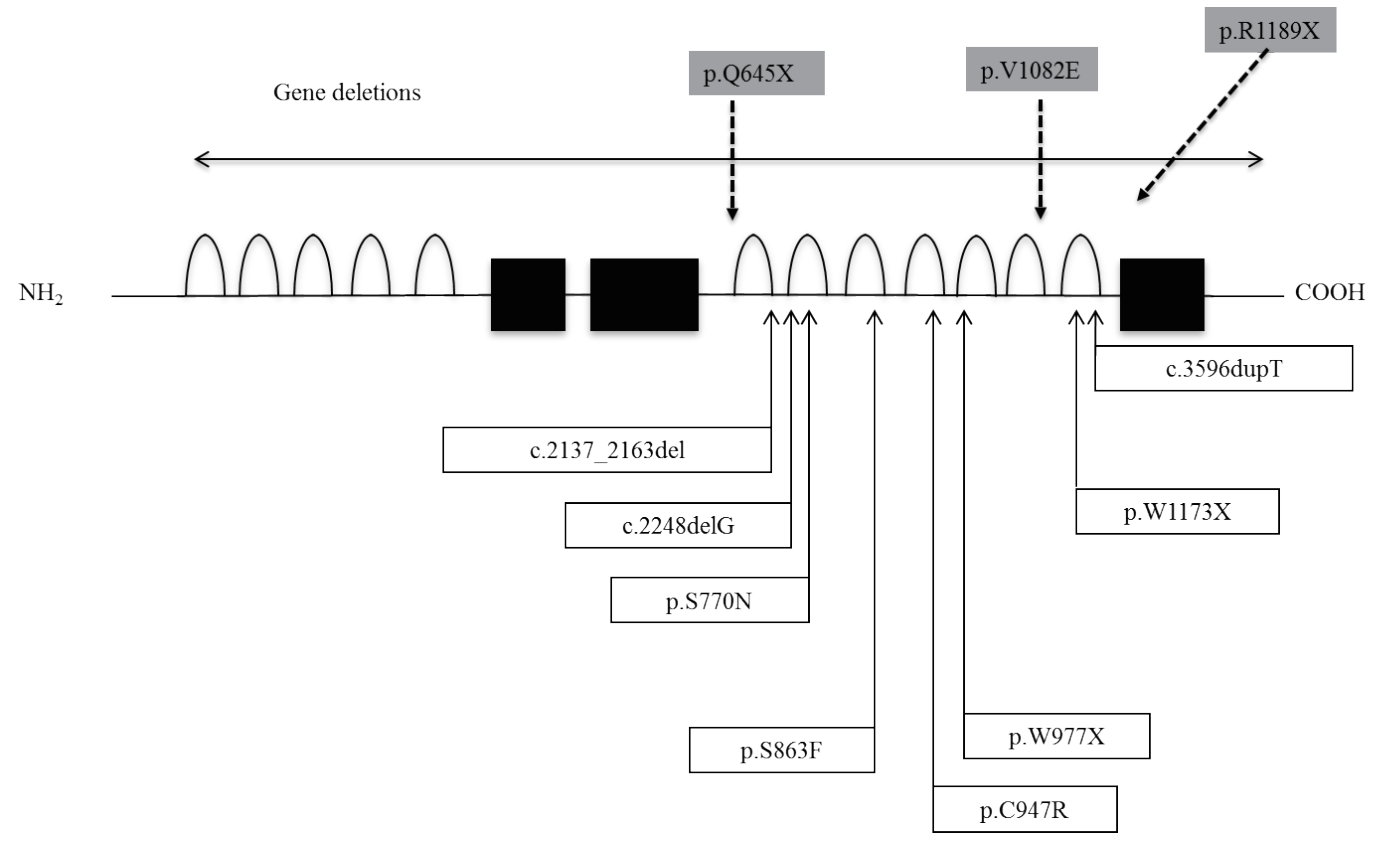

Fig. 3. Mutations/deletions of immunoglobulin superfamily member 1. Shaded boxes represent mutations we have described.

\section{Mutations/deletions of /GSF1}

Sun et al. ${ }^{14)}$ identified 8 distinct mutations and 2 deletions in IGSF1 in 11 families (Fig. 2). The mutations included in-frame deletions, single nucleotide deletions, nonsense mutations, missense mutations and one base duplication. In vitro expression studies of several mutations to analyze the functional consequences demonstrated that the encoded proteins migrated predominantly as immature glycoforms and were largely retained in the endoplasmic reticulum, resulting in decreased membrane expression ${ }^{14)}$. In Japanese patients, we have reported two nonsense mutations, one missense, and one base insertion mutation (Fig. 3). In addition, a large deletion and a splice junction mutation have been identified (unpublished data). Two patients had the R1189X mutation. From interview, they were not related, but they lived in the same prefecture and thus this mutation may be a founder effect. We also performed an in vitro study and found that the V1082E mutated product was severely impaired in its posttranslational modification and membrane trafficking, similar to results of S770N, S863F and C947R, which were previously reported.

It is likely that there is no clear genotype-phenotype correlation. Even in familial cases sharing the same IGSF1 defects, a variable degree of hypothyroidism was observed ${ }^{14,17}$. Other genetic or environmental factors may influence the phenotypic expression of IGSF1 deficiency.

\section{Conclusions}

IGSF1 deficiency is a newly-discovered cause of C-CH. The physiological role of IGSF1 is unknown, and when clarified in future, its role in the mechanisms responsible for a variety of symptoms such as hypothyroidism, PRL deficiency, macroorchidism and delayed puberty will be clearer. IGSF1 is important for the pituitary-thyroid axis and the development puberty and thus represents a new player controlling growth and puberty in childhood and adolescence.

\section{Conflict of interest}

No potential conflict of interest relevant to this article was reported.

\section{Acknowledgments}

We thank Tomoyuki Hotsubo from Department of Pediatrics, NTT East Hospital and Toru Yorifuji from Department of Pediatrics Osaka City Medical Center for Children for data of patients. We also thank Beata Bak, Jessica Lam, and Daniel J. Bernard from Department of Pharmacology and Therapeutics, McGill University for fruitful discussion and in vitro analysis of IGSF1.

\section{References}

1. LaFranchi SH. Newborn screening strategies for congenital hypothyroidism: an update. J Inherit Metab Dis 2010;33(Suppl 2):S225-33.

2. LaFranchi SH. Approach to the diagnosis and treatment of neonatal hypothyroidism. J Clin Endocrinol Metab 2011;96:2959-67. 
3. Lanting CI, van Tijn DA, Loeber JG, Vulsma T, de Vijlder JJ, Verkerk PH. Clinical effectiveness and cost-effectiveness of the use of the thyroxine/thyroxine-binding globulin ratio to detect congenital hypothyroidism of thyroidal and central origin in a neonatal screening program. Pediatrics 2005;116:168-73.

4. Fujiwara F, Fujikura K, Okuhara K, Tsubaki J, Fukushi M, Fujita K, et al. Central congenital hypothyroidism detected by neonatal screening in Sapporo, Japan (2000-2004): it's prevalence and clinical characteristics. Clin Pediatr Endocrinol 2008;17:65-9.

5. Tajima T, Jo W, Fujikura K, Fukushi M, Fujieda K. Elevated free thyroxine levels detected by a neonatal screening system. Pediatr Res 2009;66:312-6.

6. Adachi M, Soneda A, Asakura Y, Muroya K, Yamagami Y, Hirahara F. Mass screening of newborns for congenital hypothyroidism of central origin by free thyroxine measurement of blood samples on filter paper. Eur J Endocrinol 2012;166:829-38.

7. Kelberman D, Dattani MT. Role of transcription factors in midline central nervous system and pituitary defects. Endocr Dev 2009; 14:67-82.

8. Pfäffle R, Klammt J. Pituitary transcription factors in the aetiology of combined pituitary hormone deficiency. Best Pract Res Clin Endocrinol Metab 2011;25:43-60.

9. Tajima T, Ishizu K, Nakamura A. Molecular and clinical findings in patients with LHX4 and OTX2 Mutations. Clin Pediatr Endocrinol 2013;22:15-23.

10. Miyai K, Azukizawa M, Kumahara Y. Familial isolated thyrotropin deficiency with cretinism. N Engl J Med 1971;285:1043-8.

11. Hayashizaki Y, Hiraoka Y, Endo Y, Miyai K, Matsubara K. Thyroid-stimulating hormone (TSH) deficiency caused by a single base substitution in the CAGYC region of the betasubunit. EMBO J 1989;8:2291-6.

12. Collu R, Tang J, Castagne J, Lagace G, Masson N, Huot C, et al. A novel mechanism for isolated central hypothyroidism: inactivating mutations in the thyrotropin-releasing hormone receptor gene. J Clin Endocrinol Metab 1997;82:1561-5.

13. Bonomi M, Busnelli M, Beck-Peccoz P, Costanzo D, Antonica F, Dolci C, et al. A family with complete resistance to thyrotropin-releasing hormone. $\mathrm{N}$ Engl J Med 2009;360:731-4.

14. Sun Y, Bak B, Schoenmakers N, van Trotsenburg AS, Oostdijk W, Voshol P, et al. Loss-of-function mutations in IGSF1 cause an X-linked syndrome of central hypothyroidism and testicular enlargement. Nat Genet 2012;44:1375-81.

15. Tajima T, Nakamura A, Ishizu K. A novel mutation of IGSF1 in a Japanese patient of congenital central hypothyroidism without macroorchidism. Endocr J 2013;60:245-9.

16. Nakamura A, Bak B, Silander TL, Lam J, Hotsubo T, Yorifuji $\mathrm{T}$, et al. Three novel IGSF1 mutations in four Japanese patients with X-linked congenital central hypothyroidism. J Clin Endocrinol Metab 2013;98:E1682-91.
17. Joustra SD, Schoenmakers N, Persani L, Campi I, Bonomi M, Radetti G, et al. The IGSF1 deficiency syndrome: characteristics of male and female patients. J Clin Endocrinol Metab 2013;98:4942-52.

18. Mazzarella R, Pengue G, Jones J, Jones C, Schlessinger D. Cloning and expression of an immunoglobulin superfamily gene (IGSF1) in Xq25. Genomics 1998;48:157-62.

19. Robakis T, Bak B, Lin SH, Bernard DJ, Scheiffele P. An internal signal sequence directs intramembrane proteolysis of a cellular immunoglobulin domain protein. J Biol Chem 2008;283:36369-76.

20. Bernard DJ, Chapman SC, Woodruff TK. Inhibin binding protein (InhBP/p120), betaglycan, and the continuing search for the inhibin receptor. Mol Endocrinol 2002;16:207-12

21. Bernard DJ, Burns KH, Haupt B, Matzuk MM, Woodruff TK. Normal reproductive function in $\mathrm{InhBP} / \mathrm{p} 120$ deficient mice. Mol Cell Biol 2003;23:4882-91.

22. Chapman SC, Bernard DJ, Jelen J, Woodruff TK. Properties of inhibin binding to betaglycan, InhBP/p120 and the activin type II receptors. Mol Cell Endocrinol 2002;196:7993.

23. Barclay AN. Membrane proteins with immunoglobulin-like domains: a master superfamily of interaction molecules. Semin Immunol 2003;15:215-23.

24. Xu Z, Jin B. A novel interface consisting of homologous immunoglobulin superfamily members with multiple functions. Cell Mol Immunol 2010;7:11-9.

25. Ohtani H, Nakajima T, Akari H, Ishida T, Kimura A. Molecular evolution of immunoglobulin superfamily genes in primates. Immunogenetics 2011;63:417-28.

26. Babu K, Hu Z, Chien SC, Garriga G, Kaplan JM. The immunoglobulin super family protein RIG-3 prevents synaptic potentiation and regulates Wnt signaling. Neuron 2011;71:103-16

27. Irintchev $\mathrm{A}$, Schachner $\mathrm{M}$. The injured and regenerating nervous system: immunoglobulin superfamily members as key players. Neuroscientist 2012;18:452-66.

28. Yu XM, Gutman I, Mosca TJ, Iram T, Ozkan E, Garcia $\mathrm{KC}$, et al. Plum, an immunoglobulin superfamily protein, regulates axon pruning by facilitating TGF- $\beta$ signaling. Neuron 2013;78:456-68.

29. Malaguti A, Della Casa C, Castorina S, Martelli AM, Roti E, Martino E, et al. Molecular mechanisms for pituitary thyrotroph cell growth. J Endocrinol Invest 2004;27(6 Suppl):151-67.

30. Shibusawa N, Yamada M, Hirato J, Monden T, Satoh T, Mori $\mathrm{M}$. Requirement of thyrotropin-releasing hormone for the postnatal functions of pituitary thyrotrophs: ontogeny study of congenital tertiary hypothyroidism in mice. Mol Endocrinol 2000; 14:137-46.

31. Inokuchi M, Matsuo N, Takayama JI, Hasegawa T. Tracking of BMI in Japanese children from 6 to 18 years of age: reference values for annual BMI incremental change and proposal for size of increment indicative of risk for obesity. Ann Hum Biol 2011;38:146-9. 